\title{
Metabolism-modelling approaches to long-term sustainability assessment of urban water services
}

\author{
G Venkatesh ${ }^{1}$, Helge Bratteb $\emptyset^{2}$, Sveinung Sægrov1, Kourosh Behzadian ${ }^{3 *}$, Zoran \\ Kapelan $^{3}$
}

\begin{abstract}
There is a discernible need for a holistic, long-term-sustainability approach in decision-making in water and wastewater utilities around the world. Metabolism-based modelling, which can quantify various flows within an urban water system (UWS), has shown its effective usability for a more comprehensive understanding of the impacts of intervention strategies and can be used by any water utility for future planning of UWS. This study presents the main principles of a holistic Sustainability Assessment Framework which can be simulated by using two analytical, conceptual, mass-balance-based models to quantify relevant key performance indicators (KPIs) associated with the metabolic flows of the urban water cycle. These two models are WaterMet ${ }^{2}$ (WM2) and Dynamic Metabolism Model (DMM), developed recently under the aegis of the EU TRUST (Transitions to the Urban Water Services of Tomorrow) project. There are clear differences between the two models which make them useful in different contexts and circumstantial situations. DMM is a mass-balance consistent model which quantifies and presents annually-aggregated performance values for system wide energy consumption, emissions, environmental impacts and costs for the entire UWS though it is also possible to derive corresponding indicators for individual sub-systems (e.g. water distribution and wastewater transport). Opposite of this, WM2 is a distributed metabolism model which simulates water related and other resources flows throughout the UWS components with a
\end{abstract}

\footnotetext{
${ }^{1}$ Department of Hydraulic and Environmental Engineering, NTNU, Trondheim, Norway.

${ }^{2}$ Energy and Process Engineering, NTNU, Trondheim, Norway.

${ }^{3}$ College of Engineering, Mathematics and Physical Sciences, University of Exeter, UK.

* Corresponding author. E-mail: k.behzadian-moghadam@exeter.ac.uk (K. Behzadian)
} 
higher resolution both spatially (e.g. multiple water resources and service reservoirs) and temporally (e.g. daily and monthly), and thereby is useful in contexts where utilities would like to focus on further details of the UWS metabolism with the aim to understand and solve specific problems. Overall, these two complementary metabolism-based approaches enable any water utility to quantitatively explore and understand the influences of different external drivers and intervention strategies on future performance profiles linked to any physical, environmental and economic criteria.

Keywords: Urban water services, sustainability assessment, key performance indicators, WaterMet $^{2}$, Dynamic Metabolism Model (DMM).

\section{Introduction}

The decision-making process based on multiple objectives using appropriate decision support tools has become an increasing need for urban water utilities (Makropoulos et al. 2008). The objectives include elements such as water safety, climate change adaptation and mitigation, environmental life cycle assessment (LCA) and total cost efficiency. However, water utilities today often aims at covering a wide set of performance objectives (environmental, economic and social) in response to sustainability policies of cities and society in general. For instance, based on the Brundtland report cited in three references, i.e. IISD (2014), Milman and Short (2008), and Constanczak (2014), the principle of sustainability has several definitions in literature, and is applied to many different types of systems. The first reference has famously defined sustainable development as development that meets the needs of the present without compromising the ability of future generations to meet their own needs; while stressing on the essential needs of the world's poor and the limitations imposed by the state of technology and social organisation on the environment's ability to meet present and future needs (IISD 2014). The second reference has stated that it is widely agreed that any conception of sustainability must account for the interconnections of environmental, economic, and social factors; consider both the local and global resource base; and be attentive to the long-term needs of future generations environment's ability to meet present and future needs (Milman and Short 2008). The author in the last reference has defined sustainable development as 'development that meets the basic needs of all people and preserves, protects and restores the health and integrity of the 
ecosystem of earth, without jeopardizing opportunities to meet the needs of future generations and without exceeding the limits of its long-term capacity' (Constanczak 2014). Milman and Short (2008) has also considered the urban water sector as a case to investigate and recommend a number of sustainability indicators such that their selection remains flexible and they render reliability to the decision-making process. Venkatesh and Brattebø (2013), while focusing only on environmental sustainability indicators, have recommended that the selection of these for a water-wastewater utility needs to be based on concerns specific to the utility and city in question. They have also recommended the classification of cities into city-types based on specific attributes and identification of relevant environmental sustainability indicators, from a pool of 13 indicators, for these different city-types. Bratteb $\varnothing$ et al. (2011) and Brattebø et al. (2013), as parts of the EU7FP TRUST (TRansition to sustainable Urban Systems of Tomorrow) project are important recent references in this regard, which examine opportunities for strategic long-term transitions towards sustainability in urban water services. According to Brattebø et al. (2013), "Sustainability in urban water cycle services (UWCS) is met when the quality of assets and governance of the systems is sufficient to actively secure the water sector's necessary contributions to social, environmental and economic sustainability in the urban system as a whole". Sustainability assessment of UWCS should be transparent, valid and holistic, and must include the dimensions of social, environmental, economic, asset and governance sustainability. The sustainability assessment can be done by carefully examining the estimated effects of alternative interventions, and how the performance of the UWCS develops over time, using a predefined set of performance metrics or indicators. These metrics or indicators should correspond to the sustainability objectives and criteria that are important and considered meaningful for the given water utility. Brattebø et al. (2013) recommends the use of a life-cycle assessment and metabolism modelling approach in UWCS sustainability assessments, where annual emissions, environmental impacts and costs are quantified as a consequence of the physical flows (water, materials, chemicals, energy carriers, wastes) within the system, which is again a consequence of technologies, service levels, urban growth, intervention opportunities etc. The assessments methods must necessarily be inclusive and flexible with respect to stakeholder involvement and decisions regarding target-setting and trade-offs.

The TRUST project concludes a set of 13 sustainability objectives based on the five dimensions of the sustainability framework shown in Figure 1 (Brattebø et al. 2013) as follows: Social sustainability (3; S1-S3), Environmental sustainability (2; En1-En2), Economic sustainability 
(1; Ec1), Governance sustainability (4; G1-G4) and Asset sustainability (3; A1-A3). When performing a sustainability assessment for an urban water utility, the use of the TRUST framework shown in Figure 1 entails the identification and selection of one or more assessment criteria for each of the 13 objectives. Alegre et al. (2012) suggested 23 performance criteria associated with the sustainability framework in water system. Seven criteria out the 23 defined criteria are directly related to the water service coverage, the environmental and/or the economic performance of the urban water system. Furthermore, for each criterion, one or more measurable (quantitatively or qualitatively) performance metrics must be identified, and these can be further normalised in relation to desired performance levels. A framework such as the one referred to above may be applied differently, according to what the actual objective of the assessment is and what the particular challenges of a given city are. This will influence the scope (spatial and temporal boundaries) of the assessment, the choice of sustainability objectives and performance indicators/metrics, and the choice of analytical models and methods. These choices must reflect the fact that sustainability assessment should address longterm strategic changes and sustainability qualities, in contrast to a focus on more short-term operational and/or tactical interests. Leeuwen et al (2011) using the city of Rotterdam in the Netherlands as a practical example, have used a set of 24 dedicated indicators to assess the sustainability of the water cycle in the city. Van der Steen (2011), describes the steps that a local government or utility could take in order to select and implement a set of indicators to monitor, plan and manage the urban water system. Venkatesh et al (2009) and Venkatesh \& Brattebø (2011a, 2011b, 2012c, 2012a, 2012b, \& 2014) focus on the environmental aspect of sustainability for different sub-systems of the urban water system in Oslo, which incidentally is also the case considered in the current paper.

An innovative framework for assessment of water systems has been suggested by using the concept of urban metabolism (UM) (Venkatesh et al 2014). The UM, first introduced by Wolman (1965), involves quantification of the inflows, outflows, storage and production of energy and materials within the bounds of an urban setting. Such data can serve a variety of purposes, - inputs to carbon footprint analysis, determination of urban ecological footprints, or sustainability assessment in specific areas such as water use, air pollution, waste handling, resources management and etc. Recent researches have been extending UM analysis by including upstream and/or downstream environmental lifecycle impacts associated with flows into or out of urban regions (Ramaswami et al. (2008), Schulz (2010), Chavez and Ramaswami 
(2011), Chester et al. (2012)). According to Kennedy et al. (2011), the 20-odd relativelycomprehensive UM studies published thitherto in academic literature have practical applications to urban designers and planners as an adaptive approach to technological and socio-political solutions, and their consequences. The UM method basically uses static, quasistationary or dynamic material flow analysis (MFA) models (Cencic and Rechberger (2008); Baccini and Brunner (2012)). Furthermore, having determined the (metabolic) flows of a given urban system, it is also possible to estimate their corresponding potential life cycle environmental impacts, by use of life cycle assessment (LCA) methods or environmentallyextended input-output analysis (EE-IO) methods.

Integrated modelling of urban water systems has been developed extensively in the recent decade, as evidenced by conceptual models such as Aquacycle (Mitchell et al. 2001), UWOT (Makropoulos et al. 2008; Rozos and Makropoulos 2013), UVQ (Mitchell and Diaper, 2010) and CWB (Mackay and Last, 2010). These models are able to quantify water related flow and fluxes in complex urban water systems. As a supplement these models, the UM approach has recently been applied to integrated urban water system (Behzadian et al. 2014b; Behzadian and Kapelan 2015b). It can be considered that the metabolism modelling of urban water services is a subset of UM modelling. This gives opportunities for generating extensive information on the potential life cycle environmental impacts associated with the processing of the physical flows (water, materials, chemicals, energy carriers, wastes, recovered resources and etc.), in addition to information on the quantities of the physical flows themselves, in order to construct, operate and maintain the urban water system to provide services. Performance indicators can also be applied to the domain of economic performance. Model results covering the domains of physical, environmental and/or economic performance can therefore be generated, and reported on an absolute basis or on a per-cubic-metre or per-capita basis.

\section{Methods}

The metabolism of urban water services have been examined and modelled under the UM research framework, aiming at quantifying biophysical patterns of urban systems and infrastructures at different spatial and temporal scales. The methods of Material Flow Analysis (MFA) and Life Cycle Assessment (LCA) form the basis for the models applied in this study. Every urban water system (UWS) is characterized by infrastructures fulfilling the needs of water supply and wastewater collection/treatment. The UWS can be studied in-depth with 
respect to its inflow-outflow metabolic characteristics. It can be broken down into its component parts (sub-systems and if need be, sub-sub-systems) and the metabolism (inflows and outflows over time) of each of these can be studied individually, before an aggregation is done in order to understand the metabolism of the system taken as a whole.

A mass-balance-based approach has been adopted to understand how material masses flowing into a sub-system are partitioned (converted physically or chemically or not) into stocks and outflows. A time period of one year has been chosen, for instance, to aggregate the daily flows and net addition to stocks if any. Every inflow is associated with environmental impacts upstream (indirect impacts attributed to the needs of the system), and every outflow to the environment (hydrosphere, atmosphere, lithosphere and pedosphere) potentially leads to different kinds of environmental impacts (direct from the system). Outflows to the anthroposphere (cases where by-products and wastes are reused and recycled) may lead to avoidance of environmental impacts. These, for each sub-system and the time period chosen, are determined using LCA. Figure 2 illustrates the stocks and flows in a UWS; five sub-systems of which have been identified, in addition to the source and the sink. As mentioned above, these sub-systems can be split up further into sub-sub-systems. For example, the Wastewater Subsystem (component 3 in Figure 2) can be further split up into the wastewater collectionand-transport unit and the wastewater treatment unit. The UWS operates within certain preexisting geographic, climatic and socio-economic conditions which may determine its limitations as regards the extent of sustainability it can attain to. Charting the physical flows and environmental impacts, provides one with valuable information about performance, risk and the cost of operation (Ugarelli et al. 2014). The schematic sketch of the UWS in Figure 2 has been used to develop two UM models, namely WaterMet ${ }^{2}$ (WM2) and Dynamic Metabolism Model (DMM) in the TRUST project. These two UM models are briefly described in the next section in order to critically compare with each other in the following sections.

\section{Description of the UM models}

Both UM models (i.e. WM2 and DMM) are conceptual, simulation-type, mass-balance-based and integrated UWS model which quantifies metabolism-related key performance of UWS. They both use recorded data and convert them into suitable metrics / indicators, some of which can subsequently be fed into a Decision-Support-System (DSS) which enables utilities in their decision-making by factoring sustainability considerations into the mix. The stress here is on 
'some'. We are referring to the intersection set of the quantitative outputs of either model which are used as the input requirements for the DSS, as far as indicators are concerned. Some of the sustainability criteria especially qualitative ones such as public participation and acceptance of UWCS, as defined by Bratteb $\emptyset$ et al. (2011), are not addressed in the DMM and WM2 but they need to be addressed by other qualitative tools. Therefore, it should be noted that neither of these two UM models are able to calculate the entire performance indicators related to the sustainability framework in Figure 1 and thus provide a comprehensive and holistic assessment in the real sense. More specifically, the 'Social' and 'Governance' aspects cannot be addressed by these two models. As far as 'Assets' are concerned, DMM does facilitate the calculation of some indicators (Refer to Appendix I). The 'Economic' and 'Environmental' aspects (and thereby the 'Physical' aspect to which these two are related), can be quite comprehensively modelled using both DMM and WM2. The main UM flows quantified in UWS by both models include various water related flow, direct and indirect (embodied) energy, greenhouse gas emissions, chemical and material used for operation and maintenance, acidification and eutrophication potential and etc. Distinguishing features for either of the models are described here in further details.

Here, though, it would suffice to say that the DMM is a simple, flexible and modifiable, userfriendly MS-Excel-based model which accepts user-inputs in one single user-friendly file, uses inbuilt formulae, constants and 'intermediate' Excel files, and enables the end-user to test the impacts of changes expected/planned/imagined in the future, on key performance indicators (KPIs) defined under the categories: Social, Economic, Environmental, Functional and Physical. DMM presents 30 indicators which are on both per-capita and per-unit-volume-watersupplied bases (Refer Appendix I). The DMM modelling principles are based on Material Flow Analysis (MFA) and Life Cycle Assessment (LCA) methods, today widely recognized and used internationally in the fields of Industrial Ecology and Environmental Systems Analysis (Ayres and Ayres 2002, Baccini and Brunner 2012). This offers a mass-balance consistent quantification of resource inputs (materials, chemicals, energy carriers) and waste and emission outputs (greenhouse gases, nutrients, sewage sludge, etc.) per unit of water, wastewater and stormwater through flow in the system, which later are used as a basis for calculating the potential life cycle environmental impacts and costs. Readers may refer to Venkatesh et al. (2014) for more information about the structure of DMM. 
WM2 is a distributed model which is constructed based on an arbitrary number of UWS components. Simulation of the principal flows and processes in WM2 is conducted in four spatial area scales (system, subcatchment, local and indoor) with different processes supported at different scales. System area scale in WM2 enables defining the main typical components of the UWS infrastructure (i.e. water resources, water supply conduits, WTWs, trunk mains, service reservoirs, distribution mains, subcatchments, and sewer networks, WWTWs and receiving water bodies) (Behzadian et al. 2014a). Subcatchment areas in WM2 serve as 'collection points' in both simplified water supply and separate/combined sewer subsystems. Further, each subcatchment area in WM2 represents a group of neighbouring local areas, each of which is defined as a group of similar typical households (i.e. indoor area) with a surrounding area. Water demand modelling and rainfall-runoff modelling are handled at the local area scale. Water recycling schemes including rainwater harvesting and grey water recycling can be defined at local area and subcatchment scales (Behzadian et al. 2014d). The collection of wastewater/stormwater from local areas is handled in subcatchment area. Using this structure, WM2 requires the key functional characteristics of each component as input data such as storage and transport capacity, energy and cost per unit volume of water (Behzadian et al. 2014a). Water demand profiles as well as their temporal variations over the planning horizon need to be defined to consider seasonal and annual fluctuations. The WM2 spatial scales (e.g. number of subcatchments /local areas) can be used to represent a relatively large (or small) spatial area depending on the size and type of the urban area being analysed and also on the level of spatial resolution required and the available data in different scales. WM2 simulates the performance of UWS through tracking down all the modelled flows/fluxes using a daily simulation time step for typically up to a long-term period of time over the defined planning horizon.

Hence, whilst WM2 strives to embody the main functionality and complexity of the previous conceptual models for simulations of water related services (e.g. UVQ, UWOT and CWB), it quantifies other metabolism based flows/fluxes in the UWS as well. These distinguishing features enable WM2 to quantify other environmental impact categories along with water related flows. This enables water utilities which require understanding a 'big picture' of the future UWS performance under different prospective intervention strategies. WM2 as a useful simulation model can also be used for other applications in UWS such as risk analysis (Ugarelli et al. 2014), scenario-based analysis (Nazari et al. 2014a), optimisation model (Nazari et al. 
2014b) and intervention strategies Morley et al. (2014 \& 2015). Readers are referred to Behzadian et al. (2014b) and Behzadian and Kapelan (2015a) for further details of WM2.

\section{Model comparison in Oslo VAV case study}

Although both models are based on UM framework, there exist some structural differences between them, which make them useful in different contexts, situational, circumstantial conditions. Table 1 outlines the main points of difference between DMM and WM2 for a comparative overview. Recounting these differences here is to make a clear picture of both models to the readers and end-users that neither of the models is superior and can substitute the other, per se, but, depending on what the end-users' needs, goals, objectives and constraints are, one of the models would be preferable. More specifically, 'Usability' of each of these two models, in the context of their application to a case study, refers to understanding the impact of interventions on selected indicators in target year and subsequent selections which the relevant water utility will make depending on its priorities, targets and benchmarks.

Table 1: Points of difference between DMM and WM2

\begin{tabular}{|c|c|c|}
\hline Specifications & Dynamic Metabolism Model & WaterMet $^{2}$ model \\
\hline Basic structure & $\begin{array}{l}\text { Lumped model inspired by } \\
\text { industrial-ecology models }\end{array}$ & $\begin{array}{l}\text { Detailed, spatially and temporally distributed } \\
\text { simulation model inspired by a combination of } \\
\text { metabolism and conceptually based approaches. }\end{array}$ \\
\hline Interface & $\begin{array}{l}\text { User friendly interface in MS- } \\
\text { Excel }\end{array}$ & $\begin{array}{l}\text { MS Windows-based software tool with a } \\
\text { standalone GUI which enables defining an UWS } \\
\text { model by entering the data, running the } \\
\text { simulation and displaying results in Window } \\
\text { forms }\end{array}$ \\
\hline $\begin{array}{l}\text { Source code/ } \\
\text { Modifiability }\end{array}$ & $\begin{array}{l}\text { Open source using interactive } \\
\text { formulas in MS-Excel/ Easily } \\
\text { modifiable by the end-user who } \\
\text { is familiar with Excel }\end{array}$ & $\begin{array}{l}\text { Written in C\# visual Studio/ WM2 is } \\
\text { encapsulated in an executable tool. The end-user } \\
\text { is only able to change the input data in the } \\
\text { relevant form. However, any major changes can } \\
\text { only be done by either an expert familiar with the } \\
\text { software code or WM2 developers. }\end{array}$ \\
\hline $\begin{array}{l}\text { Time scales of } \\
\text { simulation }\end{array}$ & $\begin{array}{l}\text { Annual trends only and can be } \\
\text { used for a long-term horizon }\end{array}$ & $\begin{array}{l}\text { Daily time step simulation which can be } \\
\text { aggregated to weekly, monthly, annually and up } \\
\text { to a long-term planning horizon. }\end{array}$ \\
\hline Input data & $\begin{array}{l}\text { Relatively simpler and requires } \\
\text { data pertaining primarily to the } \\
\text { inflows of materials, money and } \\
\text { energy along with some } \\
\text { constants which are needed for }\end{array}$ & $\begin{array}{l}\text { In addition to all data for DMM, WM } 2 \text { needs } \\
\text { some more data such as time series of } \\
\text { weather/rainfall/ inflow to water resources and } \\
\text { material database for simulation of seasonal } \\
\text { fluctuations in water demand, water supply, }\end{array}$ \\
\hline
\end{tabular}




\begin{tabular}{|c|c|c|}
\hline Specifications & Dynamic Metabolism Model & WaterMet $^{2}$ model \\
\hline & $\begin{array}{l}\text { transforming the raw data into } \\
\text { the final processed output }\end{array}$ & $\begin{array}{l}\text { stormwater and wastewater generated plus the } \\
\text { environmental impact of materials flow. }\end{array}$ \\
\hline Spatial scales & $\begin{array}{l}\text { City-scale (lumped) analysis } \\
\text { only for main subsystems and } \\
\text { entire UWS }\end{array}$ & $\begin{array}{l}\text { Four scales including system/city, subcatchment, } \\
\text { local area and household. An arbitrary number of } \\
\text { the main UWS components can be modelled at } \\
\text { spatial scales }\end{array}$ \\
\hline Capital costs & $\begin{array}{l}\text { Modelled as a sum of } \\
\text { depreciation and annual interest } \\
\text { payments }\end{array}$ & $\begin{array}{l}\text { Capital investments of new intervention options } \\
\text { modelled in WM } 2 \text { can be calculated in the DSS } \\
\text { that is linked directly to the WM2 }\end{array}$ \\
\hline Climate change effects & Not modelled & $\begin{array}{l}\text { Modelled using time-series of weather data and } \\
\text { inflows to water resources }\end{array}$ \\
\hline $\begin{array}{l}\text { Water demand } \\
\text { modelling }\end{array}$ & $\begin{array}{l}\text { Modelled as aggregated annual } \\
\text { consumption }\end{array}$ & $\begin{array}{l}\text { Modelled by defining various fittings and } \\
\text { appliances at the household scale and per capita } \\
\text { water consumption }\end{array}$ \\
\hline Water reuse/recycling & Not modelled & $\begin{array}{l}\text { Modelled through decentralised/semi- } \\
\text { decentralised rainwater harvesting and greywater } \\
\text { recycling schemes (Behzadian et al. 2014d) }\end{array}$ \\
\hline Water quality modelling & Not modelled & $\begin{array}{l}\text { Simplified and mass balance based modelling by } \\
\text { tracking down daily flux of pollutants within } \\
\text { wastewater and urban drainage subsystems }\end{array}$ \\
\hline Modelling interventions & $\begin{array}{l}\text { Interventions can be directly } \\
\text { incorporated into the Excel } \\
\text { file/s }\end{array}$ & $\begin{array}{l}\text { Intervention options can be modelled using the } \\
\text { built-in library in the DSS tool (Morley et al. } \\
2014 \text { \& 2015) which is linked to the WM2 }\end{array}$ \\
\hline Indicators & $\begin{array}{l}\text { Expressed in per-unit-volume- } \\
\text { water-supplied and per-capita } \\
\text { terms, as required. Grouped } \\
\text { under economic, environmental, } \\
\text { functional and physical. }\end{array}$ & $\begin{array}{l}\text { Expressed in either absolute amount per unit of } \\
\text { time (i.e. day, week, month, year, planning } \\
\text { horizon) or specific amount (e.g. capita or of } \\
\text { supplied water) for each UWS components and } \\
\text { entire UWS. Indicators can be aggregated } \\
\text { spatially and temporally }\end{array}$ \\
\hline
\end{tabular}

The Oslo water utility (Oslo VAV) is a model city in the TRUST project which is used here as a case study. Oslo VAV has been considering a set of possible interventions to combat challenges (or risk factors) in the future (over the period to year-2040). These challenges include essentially population growth, asset deterioration over time, climate change and rise in industrial water consumption. Possible water scarcity would thus be the fallout of any or all of these acting in concert. Apart from these, energy efficiency improvement and thereby a truncation in the associated carbon footprint figure prominently on the agenda. Figure 3 is a self-explanatory sketch mirroring the generic sketch of Figure 2 loosely and applied to the city of Oslo. It charts the flow of raw water extracted from lakes to the water treatment plants, the flow of treated water to the water distribution system, the fulfilment of demand exerted by the consumers (which comes at the cost of leakage in the water pipelines), the discharge of wastewater (sewage and some stormwater) to the wastewater treatment plants through sewage 
collection and transport sub-system, and final outflow of untreated overflows and treated wastewater to the receiving water body which is Oslo fjord in this case.

The interventions or rather the goals which Oslo VAV is pondering over, are listed briefly hereunder (Hem, 2014). Readers are requested to refer to Venkatesh et al. (2014) for more details about the same.

The upstream interventions (water supply sub-system) are as under:

a. Reduction in per-capita water demand (all demand excluding leakage) supplied by the water treatment plants from the current value, at a uniform rate of 1\% per year, till 2040.

b. Reduction in leakage from the network, at a rate of $1 \%$ per annum for the first 3 years of the time-period being studied.

c. Installation of micro-turbines on the upstream to utilise the pressure head energy in the water flowing downhill to the water treatment plants.

d. Sourcing raw water from Holsfjorden - a source located to the west of the city, necessitating the setting up of a facility close to it, and associated piping and pumping.

e. Testing different rates of rehabilitation of the water pipeline network $(1 \%, 1.25 \%, 1.5 \%$, $2 \%, 2.25 \%$ and $2.5 \%$ ). This has been labelled as ' $\mathrm{g}$ ' as this was the most recent addition to the set (Hem, 2014)

The downstream interventions (wastewater handling sub-system) are as under:

f. Raising the rehabilitation rate of wastewater pipelines which is $1.3 \%$ in year-2013, rises to $1.6 \%$ in year-2016 and maintaining it at that level till 2040.

g. Upgrading the wastewater treatment plant at Bekkelaget.

The DMM and WM2 models were applied to the Oslo utility to model these interventions (and combinations of the same). While strategizing for each of the risk factors (or sets of risk factors), the utility would ideally have to draw up concrete long-term plans regarding not just what interventions would be adopted, but also how they would be adopted. The greater the level of detail and accuracy in the data (related to the interventions) which can be provided by the utility to the DMM and WM2, the more reliable and robust the outputs of these models will be. Having said that, of course, the models can also perform 'what-if' analyses to aid the utility in understanding the best course of action (or combination of actions) to take. For detailed results 
of these tests carried out using the two models mentioned, readers may please refer to Venkatesh et al. (2014), Behzadian et al. (2014a). The next section in the current paper presents some gleanings from the papers referred to, and highlights the usefulness of the models in different contexts and for different purposes. It is to be reiterated here that this is not an attempt to compare the models per se, but rather to contrast them, contextually.

\section{Results and discussion}

As referred to in the previous section, three dimensions (or aspects) of sustainability can be effectively addressed by the two models - Physical, Economic and Environmental. The firstmentioned, it must be pointed out though, is not one of the five defined in Figure 1. The tests yielded results for all the relevant indicators defined in the models, for all the interventions tested. Venkatesh et al. (2014) and Behzadian et al. (2014a) present some of these. In this section, however, the authors have chosen one indicator each for the three dimensions named above - Direct energy consumption (Physical; Figures 4 and 5), Systemic greenhouse gas emissions (Environmental; Figures 6 and 7) and Annual capital costs (Economic; Figures 8). Energy efficiency and reduction in GHG emissions figure prominently on Oslo VAV's agenda, as has been pointed out before.

Figures 4 and 5 plot the forecast of energy consumption in the Oslo water utility for intervention ' $d$ ' over the 30 year planning horizon. More specifically, WM2 is able to depict a monthly temporal resolution in Figure 4 (the flexibility of WM2 in choosing the temporal resolution is noteworthy here) while DMM represents normalised per-unit-water-demand of annual energy consumption in Figure 5. In addition to the total energy (indicated with the blue line), the components of the same (indicated with the red, violet and green lines) have also been indicated. WM2 includes the embodied energy in the chemicals and materials used in the calculation. The embodied energy, just to point out, is the energy expended in the production and transport of the chemicals and materials demanded by the operations within the system. DMM on the other hand, does not include this while calculating the total energy consumption in the urban water system. This becomes clear from the use of the adjectives 'direct' and 'indirect' in the Figure captions. In other words, in WM2, total energy is defined as 'direct' + 'indirect', while in DMM, it is just the total 'direct' energy consumption (electricity within the system and fossil fuel consumption if any). DMM normalises the indicator values, with respect to the start-year (in other words, divides the indicator value for given year by the corresponding value for the start 
year), and thereby the values would oscillate on either side of 1. In Figure 5, though, they are consistently less than 1 . Note that the normalised value for 2014 (i.e. 0.982) deviates somewhat from the reference value in 2013 (i.e. 1.0) since the chosen intervention (here'd') is assumed to have been implemented during 2013 before calculating the results for 2014 . Visual inspection of WM2 - and ignoring the embodied energy - does reveal that the trend depicted by both the models is more or less the same - a gradual but perceptible drop over the study-period. This can be explained intuitively by realising that water demand fulfilled keeps increasing in absolute amounts over time, and though the energy consumption which is more or less proportional to the water volumes handled, would also increase likewise, other energy demand drivers like rehabilitation for instance are totally independent of the water volumes treated and supplied.

Electricity is needed to treat raw water and wastewater, and to pump the same, while chemicals (the main reason for embodied energy demand) are consumed in water and wastewater treatment. In Oslo, fossil fuel consumption is associated with diesel use in standby generators in one of the water treatment plants, and in the pipeline network rehabilitation and maintenance phases. The spikes coincide with the spring and summer months in Oslo, when water demand (largely driven by garden-watering needs) rises. It is also in spring that snow melts and the loading on the wastewater treatment plants is higher. From Figure 7 (DMM), one can read the normalised aggregated annual per-capita GHG emissions. For that matter, one can also choose the 'per-unit-volume-water-demand' with either of the two models. Normalisation directly provides the analyst with an idea of the impact of the intervention on this indicator from the start of the test period over to its end. Due to the same reason in Figure 5, the normalised value for 2014 (i.e. 0.802) in Figure 7 deviates somewhat from the reference value in 2013 (i.e. 1.0). WM2, however, also provides the option of changing the temporal scale from daily to weekly or annual. It is also easy to obtain from WM2, graphs corresponding to Figure 6, for any subsystem one wishes to delve into. However, the general trend in both the cases (Figures 6 and 7 ), is a very gradual increase in the indicator value. In Figure 6, again, one would have to consider the sum of the blue and the green lines only in order to facilitate a proper comparison with the curve in Figure 7.

In Figure 8, the per-capita capital investments into the system in Intervention 'd' are depicted in the year in which they are committed for the purpose of bringing the new water source onstream. These are, in sooth, 'capital investments' and the information provided by WM2 has 
only a value for the amount and the timing of the investment (i.e. 720 Euro per capita in year 10). However, DMM provides capital costs (annual depreciation + interest payments; accumulated) on a per-capita basis as depicted in Figure 8. It is clearly seen that the investment committed in year-2022 introduces a spike in the graph which peaks in 2023 (as the depreciation starts from the year after the one in which the investment is made), before tapering down to a value $10 \%$ higher than the one in the start-year of the study period. Of course, here, both WM2 and DMM provide useful information. The former points to the timing and amount of the investment, and the latter gives an idea of how cumulative annual capital costs vary with time for the intervention selected.

It is of paramount importance to identify what are the indicators of relevance the utility wishes to work with and how the utility personnel would like to rank/weight these. It is a matter here of considering indicators of different types - functional (rehabilitation rate, leakage rate), environmental (GHG emissions, acidification etc., on a per-capita basis), physical (possibly pipeline material mass per capita, if lightening the network in this regard could be an objective) and economic (capital costs and O\&M expenses expressed as appropriate indicators). With regard to all the results presented above, it needs to be emphasized that if the utility has specific targets / benchmarks for a host of indicators, then the impact of different interventions or sets of interventions (which may necessarily have to be carried out), can be analysed, vis-à-vis these targets (Behzadian et al. 2014c). However, just having targets will not be enough. The different objectives may need to be prioritized or weighted, in order to arrive at an optimum solution (or a set of solutions), based on distance from the targets set for each of the indicators (Behzadian et al. 2014b). Top-priority concerns (generally from a politico-legal perspective) will inevitably trump the others during the decision-making process. The PLAN method which is being developed as part of the DSS in the EU project TRUST offers the possibility to perform the trade-offs among different interventions, including the use of weighting (Morley et al. 2015; Behzadian et al. 2015). However, this is beyond the scope of this particular study. If this had to be done, one would have needed the input of specific target values and threshold values from Oslo VAV, which have not been provided to the authors by the utility. While this unfortunately cannot be tried out for this very reason now, utilities would need to be trained to think on these lines, in order to benefit optimally from the use of these models. The importance or rather the indispensability of weighting and prioritising has been communicated to the Oslo VAV 
personnel; and quite understandably, there is an initial reluctance to do so, which hopefully will be overcome with time.

The DMM and WM2 are two UM models with different structures for representing urban water system (refer Table 1) although they both are have been developed based on the same urban metabolism approach. While the DMM is a simple, user-friendly, flexible Excel-based model, with limited capabilities, WM2 is a more sophisticated, Window-based model with a userfriendly GUI and a wider range of capabilities in different UWS components. However, neither of the two is a silver-bullet solution to all the data-management and decision-making challenges faced by utilities. Different utilities, at different points in time, for different purposes, would possibly find either of the two useful. What unites the two models however, is the basic premise on which they have been developed - the metabolism approach. Talking of usability in different contexts and for different purposes, it must be pointed out that for a general 'systemic' overview, on a year-to-year basis, which strategic managers could benefit from, and apply to decisions at the strategic level, the DMM, with its systemic outlook is suitable (recognition phase). If further decisions are to be taken, and utilities seek a tool to guide them onward, the WM2 is apt although WM2 is not the final step. More specifically, for further analysis of the strategic-level planning of the future UWS for new intervention options (feasibility study) in which the level of detail modelled may not be able to provide the detailed list of interventions to be implemented a WM2 model would be suitable. The WM2 model will definitely help identify the most promising transition path(s) into the longer-term future. The 'big-picture' type information generated in this way can then be used as an input to the next (tactical/detailed) level of planning (design phase). Hence, the next phase of WM2 modelling would need to use more sophisticated models of specifically-selected intervention options. Thus, one model complements the other.

At this juncture, it would be apt to present an extract from the feedback solicited and elicited from personnel at Oslo VAV, about their experiences with using and opinions about the two models (bearing in mind that DMM was developed in close collaboration with Oslo VAV with developers located in the same city whereas WM2 was developed in the UK). Lars Hem and Jadranka Milina from Oslo VAV tell the authors (in an e-mail correspondence received by $G$ Venkatesh, on the $6^{\text {th }}$ of August 2014) that both the DMM and WM2 models were used to evaluate the sustainability for various alternative strategies for water supply in the city in the future. According to them, the development of a metabolism model for the entire urban 
water/sanitation system using real data is a complex task involving efficient teamwork on the methodological approach, data acquisition and the verification of the model. Such models, invariably require considerable volumes of data; and the quality of the output depends on the quality of the input (which includes cost estimates for the alternative strategies one would like to test). In their opinion and rightly so, the use of cost estimates calculated from different sources or countries are likely to give erroneous results. They also stress on the fact that the quality of the output certainly would depend on trust, good communication and understanding between utilities and researchers/analysts. The fact that WM2 was developed in the UK, according to the developers of WM2, made communication a little difficult. Hem and Milina believe that the WM2 model requires more data than the DMM model; and the latter was found to be relatively simpler and more transparent (one of the points also brought out in Table 1).

To be reiterated here is the fact that DMM and WM2 provide a host of indicators, some of which are valid and useful inputs to the DSS (Morley et al. 2014). Those which are beyond the scope of the indicator-list propounded by the International Water Association, may be availed of by utilities which would need to tailor-make the decision-making process to their own specific contexts, needs and goals. The DSS thus needs to avail of other sources of input for indicators and metrics which the DMM and WM2 cannot provide (Morley et al. 2015). In other words, the sources of data for the DSS would thus be varied, with DMM and WM2 being two of them.

\section{Conclusions}

In this paper, the need for adopting a holistic outlook when it comes to sustainability assessment was stressed upon. Metabolism-modelling was advocated as an efficient approach to include the physical, economic and environmental aspects of infrastructural sustainability; in this instance, urban water systems. Thereafter, the two metabolism models - Dynamic Metabolism Model and WaterMet ${ }^{2}$ - developed under the aegis of the EU-TRUST project, with references to earlier publications in which they have been described in greater detail, were compared to each other and the fundamental differences were highlighted. The water and sanitation utility in Oslo, Oslo VAV was presented as a case study for testing these two models; and interventions which Oslo VAV have in mind for the future to counter risks related to population growth, asset deterioration, climate change etc., were referred to, again with references to earlier works by the authors. 
Based on the comparison of the two UM models, the following can be concluded:

1. Both DMM and WaterMet ${ }^{2}$ models can be used for effective quantification of 'the key aspects of technical, economic, and environmental UWS performance'. This can be especially useful when assessing the strategic level UWS performance assuming different long-term intervention strategies when addressing a range of future challenges. The models offer novel approaches on how to quantify and evaluate how alternative interventions in the UWS system over time may contribute to improve the system wide performance on key sustainability objectives and criteria. The novelty of these approaches is related to a user-friendly and flexible access to sets of predefined metrics and indicators that may be analysed at different resolution in time and space, aggregated for the overall UWS system or disaggregated for upstream or downstream subsystems.

2. DMM and WaterMet ${ }^{2}$ models can be used as complementary models to support decision-making at different phases of intervention strategic planning. The comparison in this paper suggests that DMM, with a lesser level of input data required may be more suitable for the initial, scoping and baseline type analysis while the WaterMet ${ }^{2}$ model can be more useful for further, more detailed analysis requiring additional data input for improved spatial and temporal representation of an UWS and quantification of its performance based on the simulation of different intervention strategies.

3. The outputs of both models are quantitative performance indicators which can be facilitated by availing of a suitable 'integration tool' (i.e. a decision support tool). Qualitative performance indicators representing other aspects of sustainability criteria need to be first quantified by other tools and then can be fed into the DSS.

\section{Acknowledgements}

The research leading to these results has received funding from the European Union Seventh Framework Programme (FP7/2007-2013) under grant agreement no 265122. This publication reflects only the authors' views and the European Union is not liable for any use that may be made of the information contained therein. To Lars Hem, Arnhild Krogh, and Jadranka Milina of Oslo VAV for their invaluable support with data and information over the period during which the model development and analyses were carried out. Thanks to Rita Ugarelli of SINTEF (Norway), for her useful and timely inputs. The authors finally wish to thank the three anonymous reviewers for making constructive comments which substantially improved the 
quality of the paper. Interested readers for receiving the metabolism models may contact the authors at NTNU for DMM and University of Exeter for WM2.

\section{Appendix (I)}

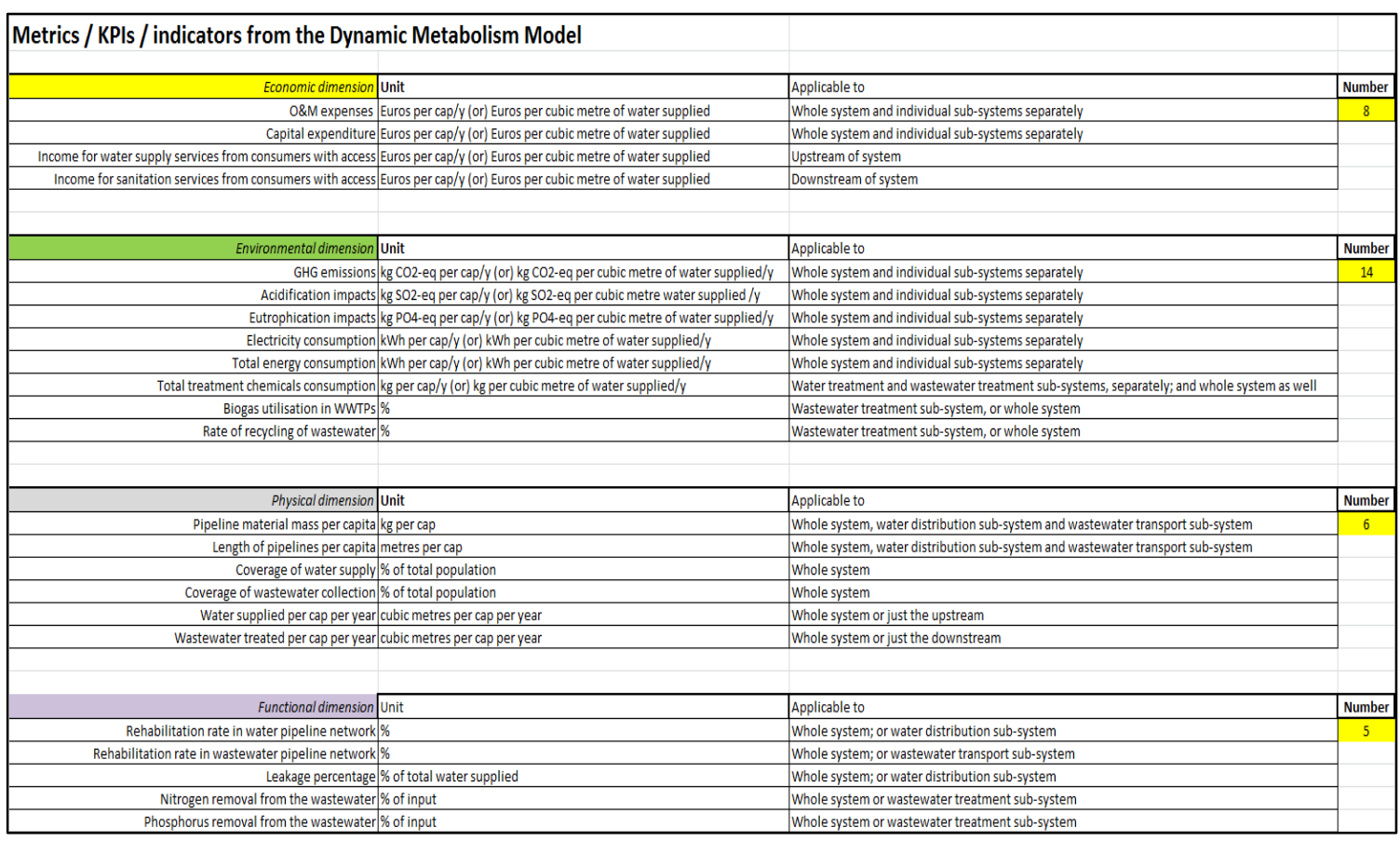




\section{References}

r Alegre, H., Cabrera, E., Hein, A. and Brattebø, H., 2012, Framework for Sustainability Assessment of UWCS and development of a self-assessment tool. Deliverable to TRUST, January 2013. (http://www.trust-i.net)

Ayres R.U. and Ayres L.W., 2002, A Handbook of Industrial Ecology. Edward Elgar, Cheltenham UK, Northhampton MA, USA.

Baccini, P., and P.H. Brunner, 2012, Metabolism of the Anthroposphere: Analysis, Evaluation Design, 2nd Edition, MIT Press

Behzadian, K., Kapelan, Z., Venkatesh, G., Brattebø, H., Sægrov, S., Rozos, E. and Makropoulos, C., 2014a. Quantitative UWCS performance model. TRUST project report, Deliverable D33.2. (http://www.trust-i.net)

Behzadian, K., Z. Kapelan, G.Venkatesh, H. Brattebø and S.Sægrov, 2014b. WaterMet²: a tool for integrated analysis of sustainability-based performance of urban water systems. Drink. Water Eng. Sci. Discuss., 7, 1-26

Behzadian, K; Kapelan, Z; G.Venkatesh; Brattebø, Helge; Sægrov, Sveinung; Rozos, Evangelos; Makropoulos, Christos; Ugarelli, Rita Maria; Milina, Jadranka; Hem, Lars, 2014c. Urban water system metabolism assessment using WaterMet ${ }^{2}$ model. Procedia Engineering, 70:113122.

Behzadian, K., Z. Kapelan, and M.S. Morley, 2014d. Resilience-based Performance Assessment of Water-recycling Schemes in Urban Water Systems. Procedia Engineering 89: 719-726.

Behzadian, K; Kapelan, Z., 2015a. Modelling Metabolism Based Performance of an Urban Water System using WaterMet ${ }^{2}$. Resources, Conservation and Recycling, in press.

Behzadian, K; Kapelan, Z., 2015b. Advantages of Integrated and Sustainability based Assessment for Metabolism based Strategic Planning of Urban Water Systems. Submitted to Science of the Total Environment.

Behzadian, K; Morley M., Vitorino D., Coelho S., Ugarelli R., Kapelan, Z., 2015. DSS methodology, software and case study from a pilot city. TRUST project report, Deliverable D54.3. (http://www.trust-i.net).

Brattebø, H., Sægrov, S., and G Venkatesh, 2011. "Metabolism modelling of urban water cycle systems - System definition and scoping report", TRUST, Internal deliverable, WA 3.3. (http://www.trust-i.net) 
Brattebø, H., Alegre, H., Cabrera, E., Marques, R.C., Hein, A. and Cruz, C.O., 2013. A Master Framweork for UWCS Sustainability. Deliverable to TRUST D 31.1. (http://www.trust-i.net) Brunner, P.H., Rechberger, H., 2004. Practical handbook of material flow analysis. Lewis Publishers. New York. USA. ISBN 1-5667-0604-1.

Cencic, O., Rechberger, H., 2008. Material Flow Analysis with Software STAN, J. Environ. Eng. Manage. 18(1), 3-7

Chavez A, and Ramaswami A, 2011, Progress toward low carbon cities: approaches for transboundary GHG emissions' footprinting. Carbon Management, 2: 471-482.

Chester, M., Pincetl, S., and Allenby, B., 2012. Avoiding Unintended Tradeoffs by Integrating Life-cycle Impact Assessment with Urban Metabolism, Current Opinion in Environmental Sustainability, 4(4), 2012, 451-457

Constanczak, S, 2014. Theory of sustainable development and social practice. Problemy Ekorozwoju, 9(1), 37-46.

Hem, L., 2013. Oslo Water and Wastewater Authority, Oslo, Norway. Personal communication in Trondheim.

IISD (International Institute for Sustainable Development). Accessed at http://www.iisd.org/sd, on $4^{\text {th }}$ September 2014

Kennedy, C., Pincetl, S., Bunje, P., 2011. The study of urban metabolism and its applications to urban planning and design. Environmental Pollution 159 (8-9), 1965-1973.

Mackay, R., Last, E., 2010. SWITCH city water balance: a scoping model for integrated urban water management. Reviews in Environmental Science and Bio/Technology 9(4), 291-296.

Makropoulos, C.K., Natsis, K., Liu, S., Mittas, K., Butler, D., 2008. Decision support for sustainable option selection in integrated urban water management. Environmental Modelling \& Software 23(12) 1448-1460.

Milman A and Short A, 2008. Incorporating resilience into sustainability indicators: An example for the urban water sector. Global Environmental Change 18, 758-767.

Morley M., K. Behzadian, Z. Kapelan, R. Ugarelli, Decision Support System for Metabolismbased Transition to Urban Water Systems of Tomorrow, IWA, IWA World Water Congress \& Exhibition, Lisbon Portugal; 2014.

Morley M., D. Vitorino, K. Behzadian, R. Ugarelli, Z. Kapelan, S.T.Coelho, M. Céu Almeida, Decision Support System for the Long-Term City Metabolism Planning Problem, IWA, Proceeding of IWA Cities of the Future Conference, TRUST2015, Mulheim Germany; 2015. 
Iะ Nazari, S., Mousavi, S. J., Behzadian, K., Kapelan, Z., 2014a. Compromise Programming Based Scenario Analysis Of Urban Water Systems Management Options: Case Study of Kerman City, Proceeding of Hydroinformatic conference (HIC), New York, US.

Nazari, S., Mousavi, S. J., Behzadian, K., Kapelan, Z., 2014b. Sustainable Urban Water Management: A Simulation Optimization Approach, Proceeding of Hydroinformatic conference (HIC), New York, US.

Paus R and Hem L, 2012. KVU Vannforsyning Oslo - Innfasing av ny vannkilde. For NorConsult. SINTEF. NIVA. dated 30-5-2012

Ramaswami A, Hillman T, Janson B, Reiner M, Thomas G., 2008. A demand-centered, hybrid life-cycle methodology for city scale greenhouse gas inventories. Environ Sci Technol 42: 6455-6461.

Rozos, E., and C. Makropoulos, Source to tap urban water cycle modelling, Environmental Modelling and Software, 41, 139-150, doi:10.1016/j.envsoft.2012.11.015, Elsevier, March 2013.

Schulz N.B., 2010. Delving into the carbon footprints of Singapore - comparing direct and indirect greenhouse gas emissions of a small and open economic system. Energy Policy, 38: 4848-4855.

Ugarelli, R., Almeida, M. C., Behzadian, K., Liserra, T., Smeets, P., Kapelan, Z., \& Sægrov, S., 2014, Sustainability Risk Based Assessment of The Integrated Urban Water System: A Case Study Of Oslo. Proceeding of Hydroinformatic conference (HIC), New York, US

Van Leeuwen, C.J., J. Frijns, A. van Wezel. 2011. Indicators for the sustainable urban water cycle. BTO 2011.027(s). KWR Watercycle Research Institute, Delft, The Netherlands

Van der Steen, Peter, 2011. Application of Sustainability Indicators within the framework of Strategic Planning for Integrated Urban Water Management. A training manual for Process Facilitators of Urban Strategic Planning processes. Deliverable 1.1.7. 018530 - SWITCH Sustainable Water Management in the City of the Future.

- VAV, 2006. Water Supply Sewerage and Environment Customer Services Finances and Rates Organisation. Oslo Water and Sewerage Works: Oslo, Norway.

VAV, 2011a. 'Forecast of Water Usage in the Future in Oslo' translated from the original r Norwegian version to English by G Venkatesh 'Water Treatment Plant Bulletin' by Oslo Water. Oslo Water and Sewerage Works: Oslo, Norway. 
VAV, 2011b. 'Rough Analysis of Alternatives' translated from the original Norwegian version to English by G Venkatesh 'Water Treatment Plant Bulletin' by Oslo Water. Oslo Water and Sewerage Works: Oslo, Norway.

VAV, 2013. Hovedplan - Avløp og Vannmiljø (Masterplan - Sewage and the hydrosphere). 11 December 2013.

Venkatesh, G., 2011, PhD thesis - Systems Performance Analysis of Oslo's Water and Wastewater System. Norwegian University of Science and Technology. Trondheim. Norway7491. ISBN 978-82-471-2623-3.

Venkatesh, G., Brattebø H., 2011a. Environmental impact analysis of chemicals and energy consumption in wastewater treatment plants: Case study of Oslo. Norway. Water Science and Technology 63(5), 1018-1031.

Venkatesh, G. and Brattebo H., 2011b, Energy consumption, costs and environmental impacts for urban water cycle services: Case study of Oslo (Norway). Energy 36(2), 792-800.

Venkatesh, G. and Brattebo H. 2011c. Analysis of chemicals and energy consumption as cost components in water and wastewater treatment: Case study of Oslo. Norway. Urban Water Journal 8 (3), 189-202.

Venkatesh, G. and Brattebø H., 2012a. Assessment of environmental impacts of an ageing and saturated water supply pipeline network - City of Oslo. 1991-2006. Journal of Industrial Ecology 16(5), 722-734.

Venkatesh, G. and Brattebø H., 2012b. Environmental impact analysis of chemicals and energy consumption in water treatment plants: Case study of Oslo. Norway. Water Science and Technology-Water Supply 12(2), 200-211.

Venkatesh, G. and Brattebø H., 2013. Typifying cities to streamline the selection of relevant environmental sustainability indicators for urban water supply and sewage handling systems: a recommendation. Environment Development and Sustainability. 15(3): 765-782.

Venkatesh, G and Brattebø H., 2014. Studying the demand-side vis-à-vis the supply-side of urban water systems -Case study of Oslo, Norway. Environmental Technology. 35(18): 2322-2333. Venkatesh, G., Hammervold, J., Brattebø, H., 2009. Combined MFA-LCA of wastewater pipeline networks: Case study of Oslo. Norway. Journal of Industrial Ecology 13(4), 532-549. Venkatesh G., Brattebø H. and Sægrov S., 2014. Dynamic metabolism modeling of urban water services - demonstrating effectiveness as a decision-support tool for Oslo, Norway. Water Research, Vol 61: 19-33.

Wolman, A., 1965. The metabolism of cities. Scientific American 213(3), 179-190. 


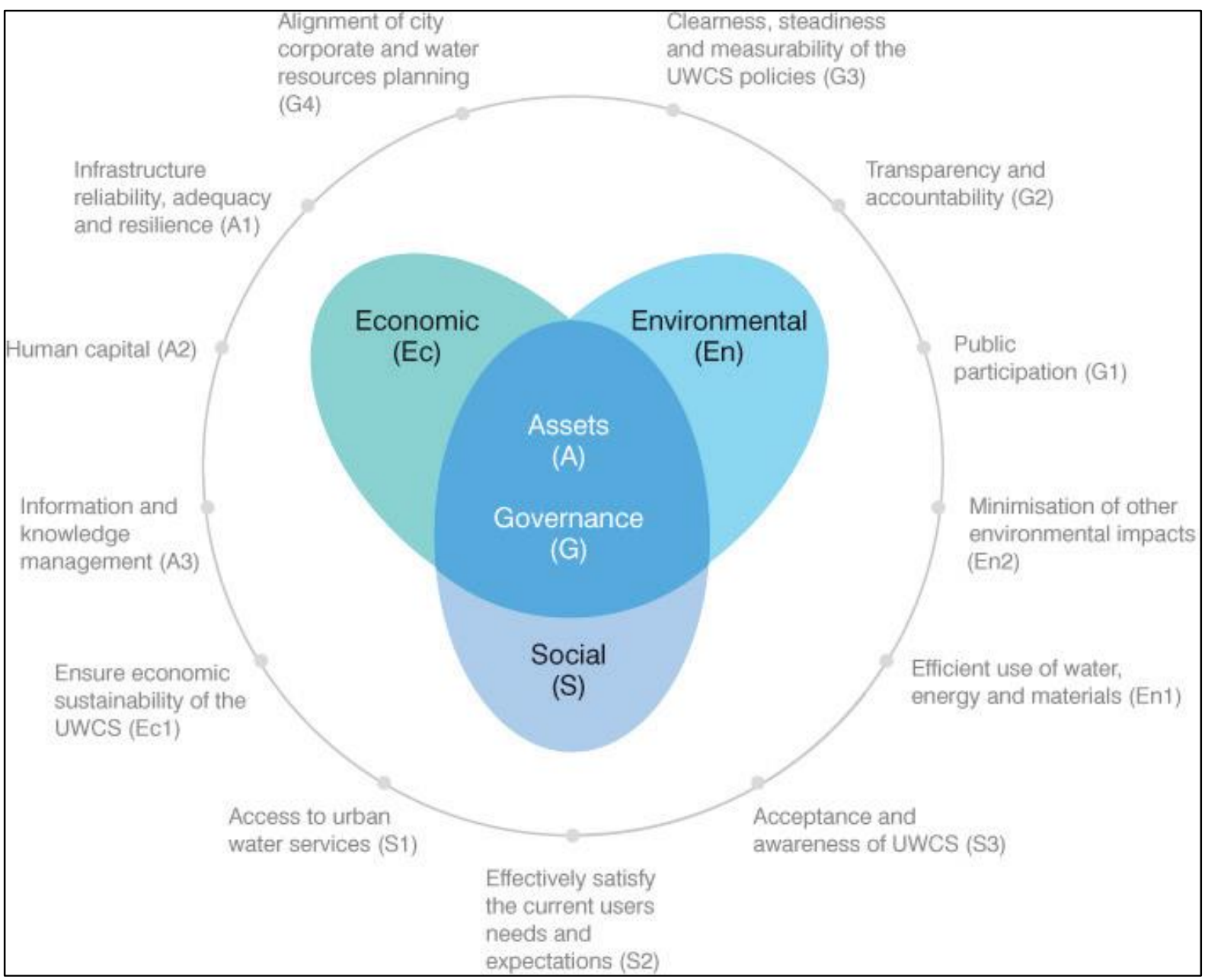

I Yq Figure 1: TRUST project framework for sustainability assessment of urban water services 
(Geographic, Climatic, Socio-economic)

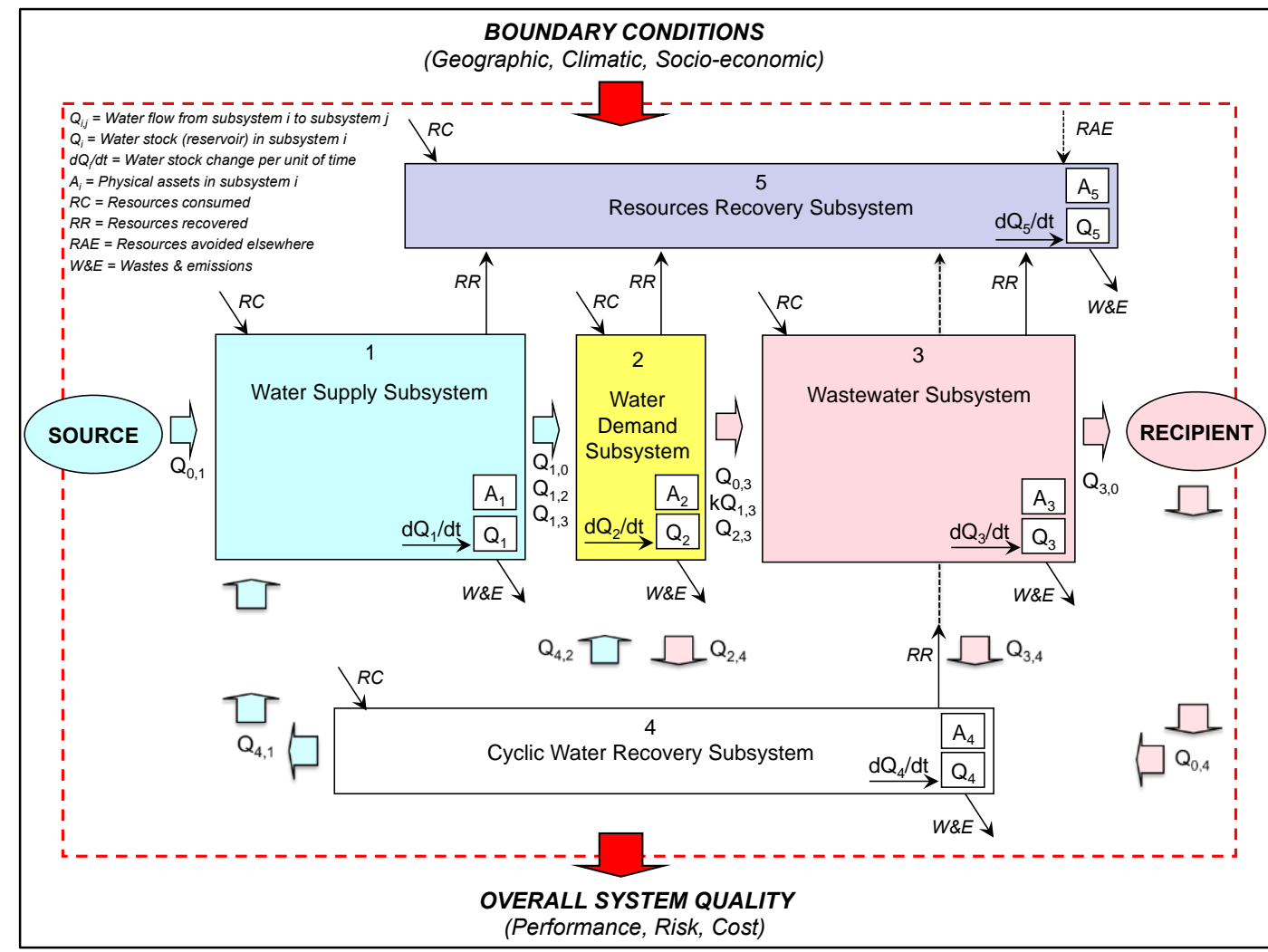

1r) Figure 2: Urban water cycle system with metabolic flows

Y

سب

1)

o

עץ

ITV

I H 


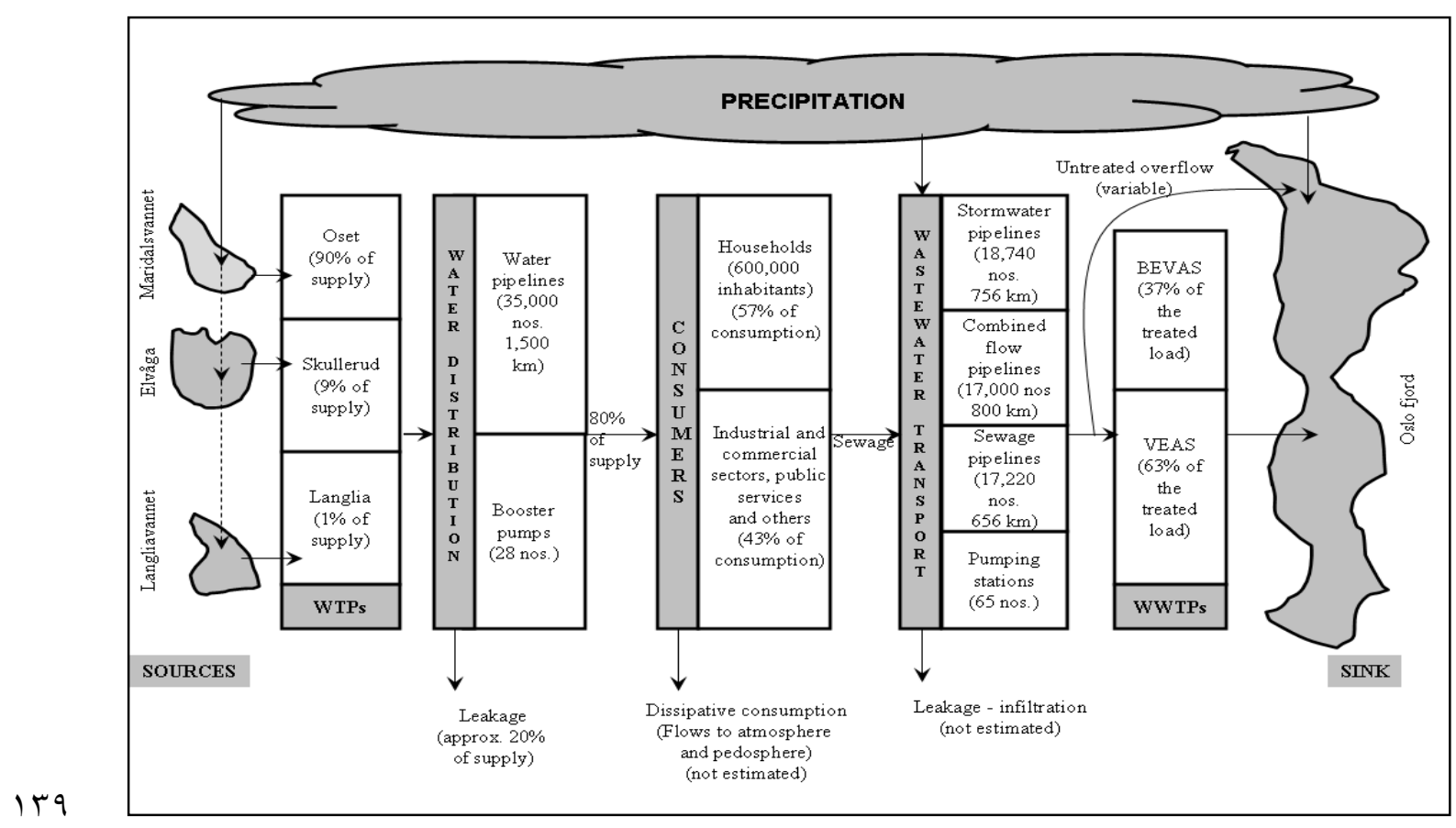

I乏. Figure 3: UWCS in Oslo - from surface water sources to the sink (Oslo fjord)

$\mid \leqslant 1$

$1 \leqslant r$

$1 \leqslant r$

$1 \leqslant \varepsilon$

$1 \leqslant 0$

$1 \leq 7$

$1 \leqslant V$

$1 \leqslant \wedge$

$1 \leqslant 9$ 


\section{Energy (Urban Water System)}

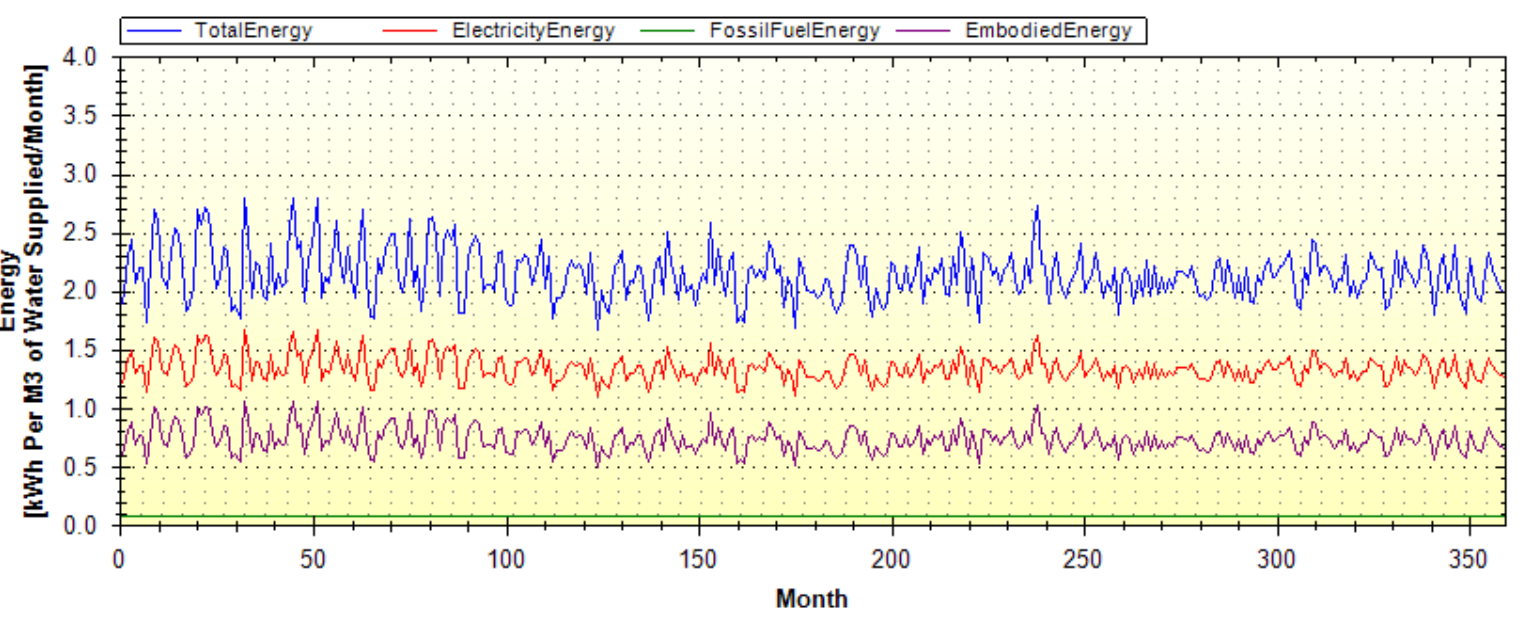

10) Figure 4: WM2 - Direct and indirect systemic absolute monthly energy consumption, in lor Intervention ' $d$ '

104

$10 \leqslant$

100

107

$10 \mathrm{~V}$

101

109 
17.

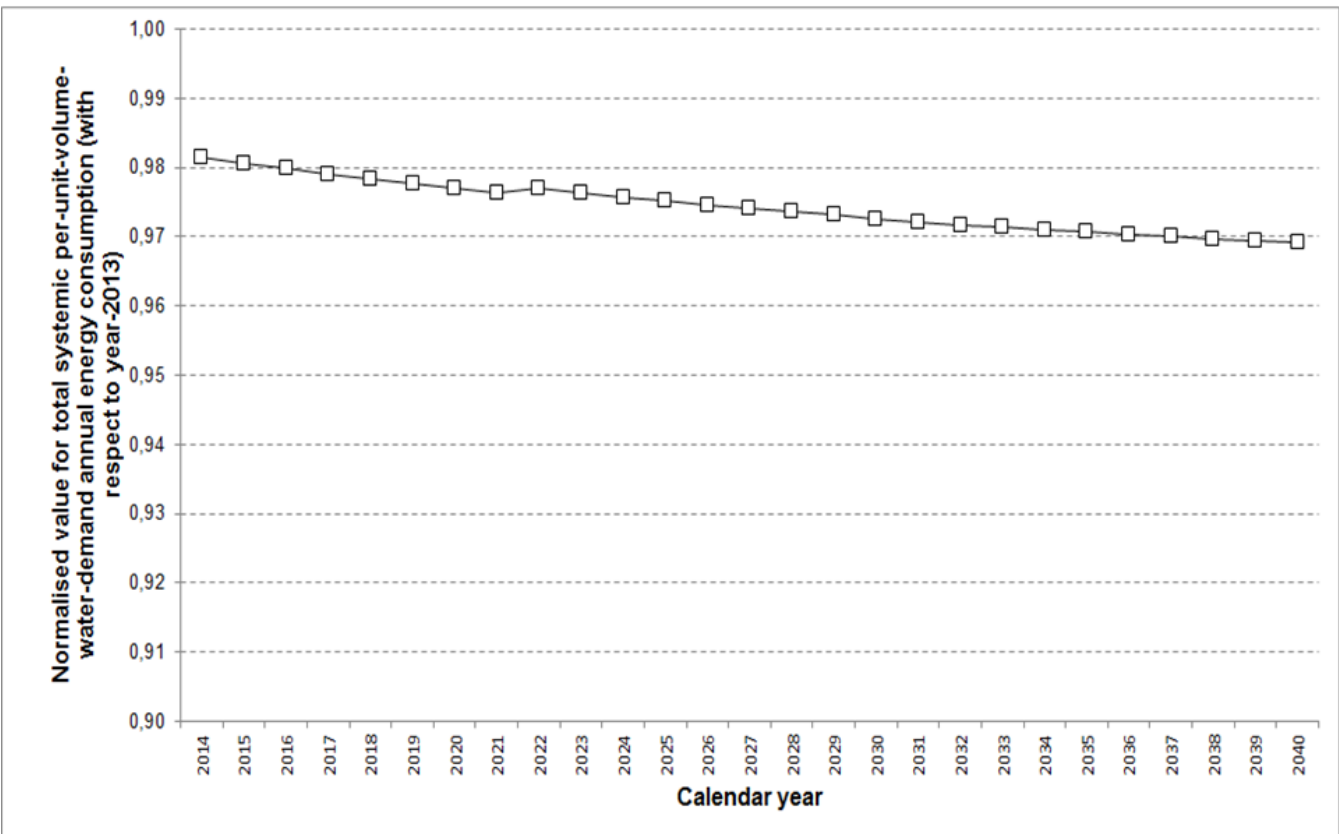

Figure 5: DMM - Annual, per-unit-water-demand, direct systemic energy consumption normalised with respect to year-2013, in Intervention ' $d$ '; note that value 1.00 is $100 \%$ of reference year value in 2013 .

$17 \varepsilon$

170

177

$17 V$

171

179

IV.

IVI 


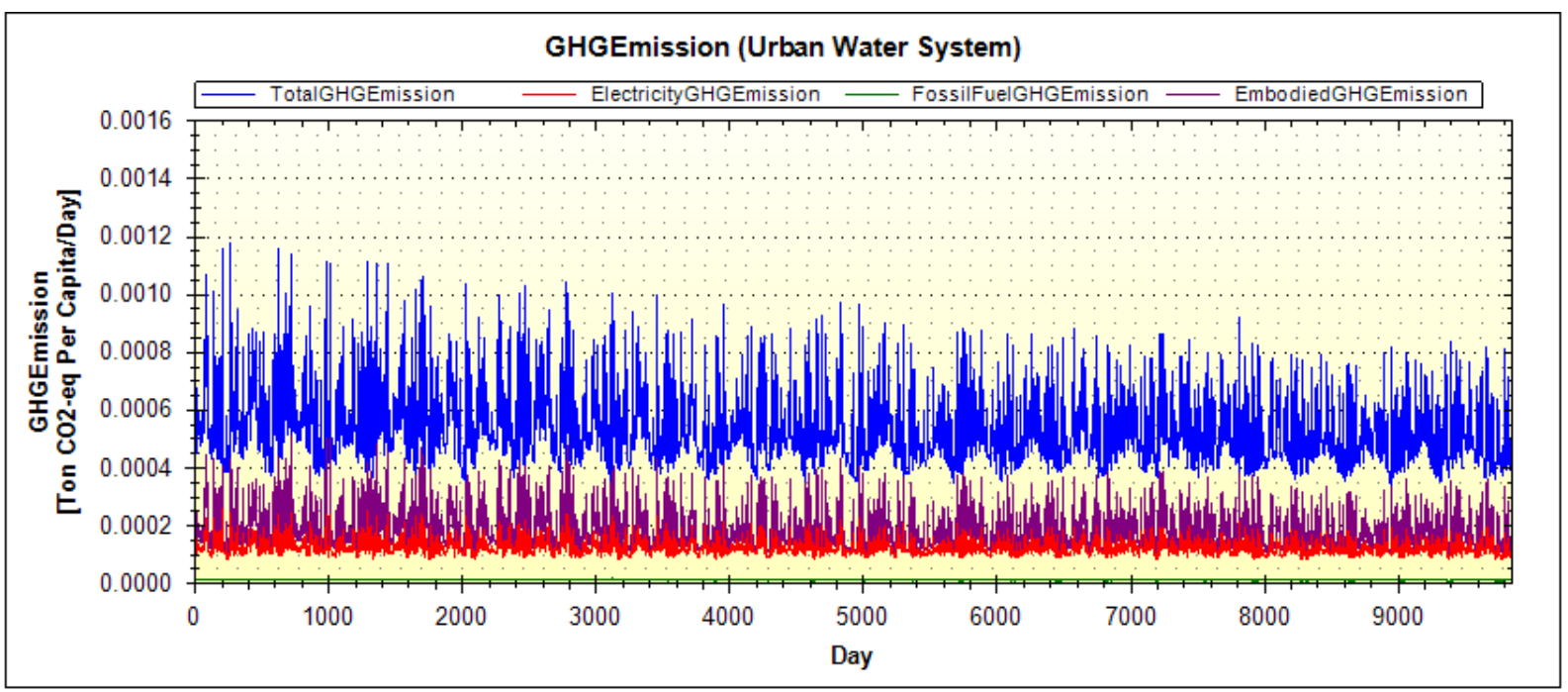

IVr Figure 6: WM2 - Absolute daily GHG emissions in Oslo urban water system, under IV $\vee$ Intervention ' $d$ '.

1Vo

IVT

IVV

IVA

119

$1 \wedge$.

|人 1

lNr

וN 


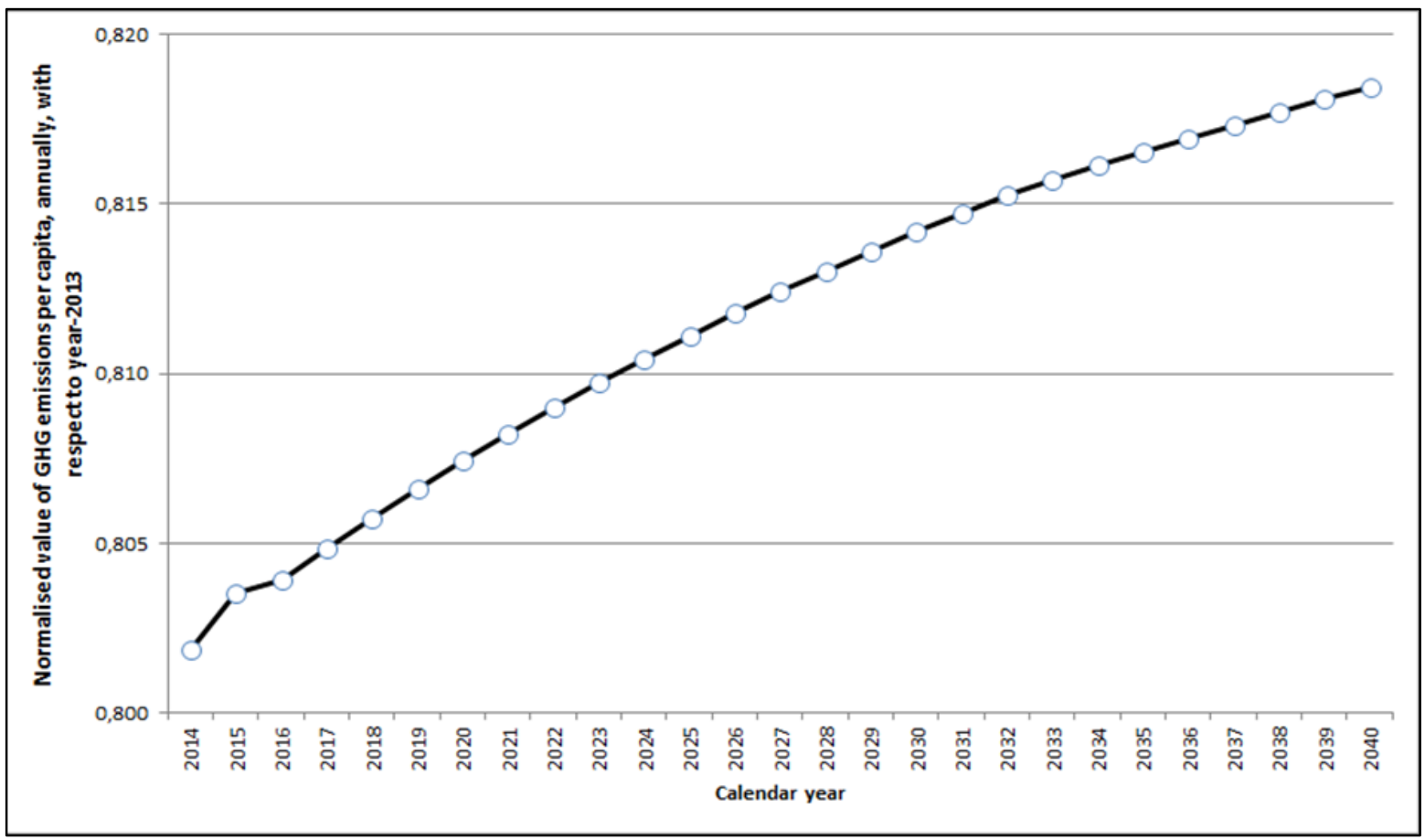

110 Figure 7: DMM - Annual per-capita GHG emissions in Oslo urban water system, under

INT Intervention 'd'; note that the values were normalised with respect to year-2013 and thus IAV value 1.00 is $100 \%$ of reference year value in 2013 .

$1 \wedge 1$

119

19.

191

194

194

195

190

197 


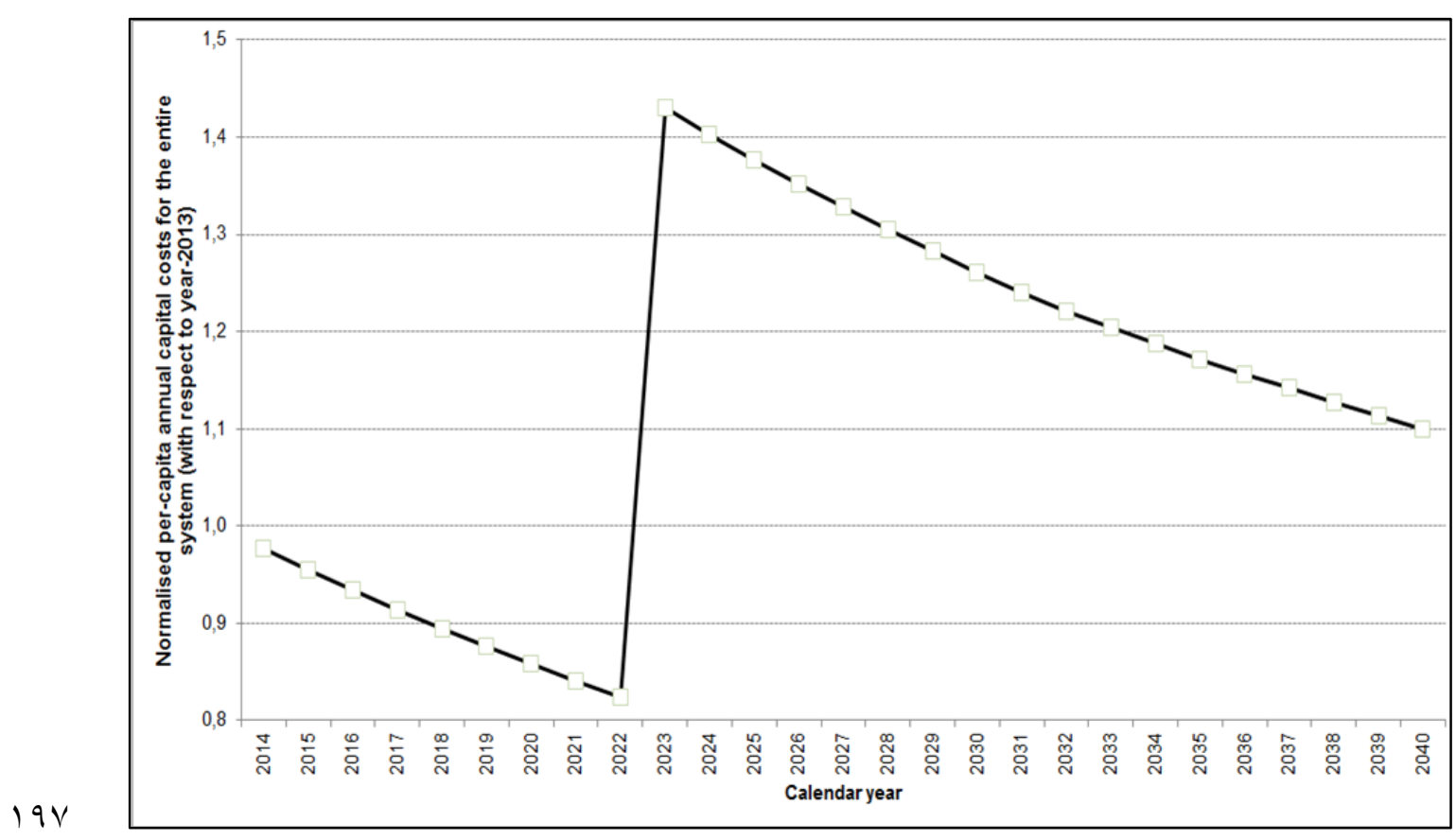

191 Figure 8: DMM - Annual per-capita capital costs, normalised with respect to year-2013, in 199 Intervention 'd' (calculated as annual cumulative depreciation + annual interest payments); note r.. that value 1.00 is $100 \%$ of reference year value in 2013 .

$r \cdot r$
$r \cdot r$ 